\title{
A case report and brief review of the literature on bilateral retinal infarction following cardiopulmonary bypass for coronary artery bypass grafting
}

Brian A Trethowan ${ }^{1,2^{*}}$, Helen Gilliland ${ }^{1}$, Aron F Popov², Barathi Varadarajan', Sally-Anne Phillips ${ }^{1}$, Louise McWhirter ${ }^{1,3}$ and Robert Ghent ${ }^{1}$

\begin{abstract}
Postoperative visual loss is a devastating perioperative complication. The commonest aetiologies are anterior ischaemic optic neuropathy (AION), posterior ischaemic optic neuropathy (PION), and central retinal artery occlusion (CRAO). These appear to be related to certain types of operation, most commonly spinal and cardiac bypass procedures; with the rest divided between: major trauma causing excessive blood loss; head/neck and nasal or sinus surgery; major vascular procedures (aortic aneurysm repair, aorto-bifemoral bypass); general surgery; urology; gynaecology; liposuction; liver transplantation and duration of surgery. The non-surgical risk factors are multifactorial: advanced age, prolonged postoperative anaemia, positioning (supine $v$ prone), alteration of venous drainage of the retina, hypertension, smoking, atherosclerosis, hyperlipidaemia, diabetes, hypercoagulability, hypotension, blood loss and large volume resuscitation. Other important cardiac causes are septic emboli from bacterial endocarditis and emboli caused by atrial myxomata. The majority of AION cases occur during CPB followed by head/neck surgery and prone spine surgery. CPB is used to allow coronary artery bypass grafting on a motionless heart. It has many side-effects and complications associated with its use and we report here a case of bilateral retinal infarction during routine coronary artery bypass grafting in a young male patient with multiple risk factors for developing this complication despite steps to minimise its occurrence.
\end{abstract}

\section{Case Report}

A 36 year-old Caucasian male (59 kg, BMI $23.8 \mathrm{~kg} \cdot \mathrm{m}^{-2}$ ) presented for urgent coronary artery bypass grafting 4 weeks after admission to the coronary care unit with a non-ST elevation myocardial infarction. He had episodic chest pain for 1 year increasing in frequency over six weeks prior to admission. On admission to hospital he was commenced on medication including acetylsalicylic acid, Clopidogrel, Elantan LA, Bisoprolol, Ramipril, Ezetimibe and Enoxaparin and he remained as an inpatient until his scheduled surgical procedure without requiring heparin, GTN infusion or inotropes. Urgent coronary angiography revealed a critical lesion of the left main

\footnotetext{
* Correspondence: briantrethowan@hotmail.com

'Department of Anaesthesia, Royal Group of Hospitals and Dental Hospital Health and Social Services Trust, Grosvenor Road, Belfast, BT12 6BA, Northern Ireland

Full list of author information is available at the end of the article
}

stem artery, $70 \%$ stenosis of the proximal circumflex and $70 \%$ stenosis of the origin of the posterior descending artery and moderate impairment of left ventricular function with inferoposterior hypokinesis. This impairment in left ventricular was confirmed by transthoracic echocardiography. On arrival in the anaesthetic room his initial blood pressure was recorded as $90 / 50 \mathrm{mmHg}$ and this had no apparent effect on pre-operative organ function considering all blood tests were within normal range and urine output was $>1 \mathrm{ml} \cdot \mathrm{kg}^{-1} \cdot \mathrm{hr}^{-1}$. General anaesthesia was induced and was further maintained with propofol target-controlled infusion $\left(1.5 \mu \mathrm{g} . \mathrm{ml}^{-1}\right)$, remifentanil $\left(0.34 \mu \mathrm{g} \cdot \mathrm{kg}^{-1} \cdot \mathrm{min}^{-1}\right)$ and isoflurane/oxygen/ air mix at $\mathrm{FiO}_{2}$ of 0.4 and end-tidal isoflurane 0.4-0.6\%. Peri-operative transoesophageal echocardiography was used as part of monitoring in this case and epi-aortic ultrasound scanning was not utilised. As the left internal

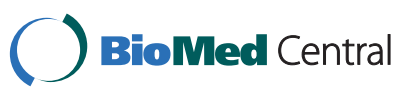


mammary artery was being taken down a dose of 250 $\mathrm{mg}(4.3 \mathrm{mg} / \mathrm{kg})$ of heparin was given with a subsequent ACT of 559s. During CPB mean arterial pressure was maintained between 50-60 mmHg using boluses of phenylephrine and subsequently an infusion of noradrenaline. The lowest recorded mean arterial pressure was 45 $\mathrm{mmHg}$ immediately post institution of CPB. The infusion of noradrenaline ran at doses from $0.05-0.075 \mu \mathrm{g} . \mathrm{kg}$ ${ }^{1}$. $\mathrm{min}^{-1}$ throughout the procedure. Other drugs that were used include glyceryl trinitrate at $0.5 \mathrm{mg} \cdot \mathrm{hr}^{-1}$ as well as an infusion of the synthetic anti-fibrinolytic tranexamic acid initially at $1000 \mathrm{mg} \cdot \mathrm{hr}^{-1}$ reduced to 600 $\mathrm{mg} \cdot \mathrm{hr}^{-1}\left(0.2 \mathrm{mg} \cdot \mathrm{kg}^{-1} \cdot \mathrm{min}^{-1}\right)$ to reduce perioperative blood loss. He received an infusion of milrinone at a dose $2 \mu \mathrm{g} \cdot \mathrm{kg}^{-1} \cdot \mathrm{min}^{-1}$. Mixed venous saturation ranged from $55-70 \%$ in the peri-operative period. Pre-operatively the $\mathrm{Hb}$ concentration was 11.5 g.dl ${ }^{-1}$. Intra-operatively the range of $\mathrm{Hb}$ was 7.5-10.5 g. $\mathrm{dl}^{-1}$ with the nadir on admission to CSICU. He was cooled and reached a nadir of $30^{\circ} \mathrm{C}$. He was successfully weaned from $\mathrm{CPB}$ after placement of an intra-aortic balloon pump (IABP) and continuation of vasopressor and inotropic support. On admission to the Cardiac Surgical intensive care unit (CSICU) his mean blood pressure was $60 \mathrm{mmHg}$ with a mean PA pressure of $14 \mathrm{mmHg}$. The balloon pump counter-pulsation remained on a 1:1 ratio with noradrenaline $0.05 \mu \mathrm{g} \cdot \mathrm{kg}^{-1} \cdot \mathrm{min}^{-1}$, dopamine $5 \mu \mathrm{g} \cdot \mathrm{kg}^{-1} \cdot \mathrm{min}^{-1}$, adrenaline $0.075 \mu \mathrm{g} \cdot \mathrm{kg}^{-1} \cdot \mathrm{min}^{-1}$, and milrinone $1.5 \mu \mathrm{g} \cdot \mathrm{kg}^{-1} \cdot \mathrm{min}^{-1}$ to maintain a mean pressure of $75 \mathrm{mmHg}, \mathrm{CI}>2.2$ and adequate urine output $>0.5 \mathrm{ml} \cdot \mathrm{kg}^{-1} \cdot \mathrm{hr}^{-1}$. The Hb concentration immediately on admission to CSICU post-operatively was $6.4 \mathrm{~g}^{\mathrm{dl}} \mathrm{l}^{-1}$, he was transfused with 3 units of packed cells and thereafter it remained between 8-10 g. $\mathrm{dl}^{-1}$. On arrival in CSICU it was noted that his pupils were fixed and dilated at $5 \mathrm{~mm}$. His intraocular pressure (IOP) was measured and found to be $13 \mathrm{mmHg}$. The measure of intraocular pressure served to rule out glaucoma and was a surrogate for measurement of intracranial pressure (ICP). During a sedation hold he was able to respond to command appropriately. The intra-aortic balloon pump was weaned quickly post-operatively and removed just over 12 hours after admission to CSICU. On the second day post-operatively whilst being turned he suffered a brief asystolic arrest requiring approximately 1 minute of CPR before return of spontaneous circulation, with similar pre-arrest haemodynamics. There was no warning of this from haemodynamic monitoring and on review of the charts the acute nature of the incident would appear to fit with a failure of pacing capture. However, subsequent urgent transesophageal echocardiography showed non-compressive clot and fluid around the right atrium, with CVP of 10-12 and mean PAP $16 \mathrm{mmHg}$. He returned to theatre for a re-exploration of his pericardium at which time a small amount of clot was removed and no revision of pacing wires was required. Over the next 36 hours he was weaned from all inotropic and vasopressor medications. He was extubated on day 3 post-operatively, had normal vision at this stage and was able to see staff within CSICU despite still having fixed and dilated pupils. $\mathrm{He}$ was re-intubated on day 5 after a failed trial of noninvasive therapy for bibasal collapse and worsening oxygenation. 7 days post-operatively, after being extubated for the second time, the patient complained of poor vision. An urgent ophthalmology review was organised and their findings were as follows: visual acuity showed no perception of light bilaterally, both pupils fixed and dilated, unreactive to light or accommodation, no consensual response, normal intraocular pressure, good red reflex, bilateral disc pallor, indistinct disc margins, retinal pallor at posterior pole, cattle-trucking of retinal arterial circulation. He also had bilateral internuclear ophthalmoplegia with up-gaze and down-gaze weakness. The impression was one of bilateral anterior ischaemic optic neuropathy (AION) and impending bilateral central retinal artery occlusion (CRAO) with brain stem involvement. A CT brain showed marked calcification of the falx, tentorium and choroid plexus with a further abnormality in the corpus callosum representing an unusual area of focal ischaemia (most likely in keeping with recent cardiac surgery). Rescue therapy with acetazolamide and topical timolol to reduce IOP and improve intraocular perfusion pressure, despite normal IOP, was attempted, but there was no improvement in vision. During follow up by neurology and ophthalmology services within the hospital he underwent a MRI of his brain with Magnetic Resonance Angiography of his cerebral vessels. No white matter abnormality was identified within cerebral hemispheres and the brainstem, cerebellum and pituitary fossa were unremarkable. $\mathrm{He}$ was also referred to a clinical psychologist and the Royal National Institute for the Blind (RNIB) for support and rehabilitation.

\section{Discussion}

The incidence of postoperative visual loss ranges from $0.0008 \%-0.002 \%$ in non-ocular, non-cardiac surgery to $0.06-4.5 \%$ in CPB series [1-9]. The most common postoperative visual loss defects are related to ischaemic optic neuropathy (ION) CRAO and cortical blindness [1]. There is still much controversy surrounding this injury and it appears it is not always preventable. Should we however inform all patients of the risk given the incidence of post-operative visual loss is rare but devastating? The lack of certainty of the mechanism of the insult limits our understanding combined with the multiplicity of risk factors. The rodent model described by Bernstein is of uncertain importance as most evidence is 
from case-series or case-control studies in cardiac, spinal, trauma and non-ocular surgery [2,4-6,8,10,11].

In this case report, we will restrict our discussion to the aetiology and mechanisms pertaining to ION describing the clinical findings and mechanism of both AION and PION. AION occurs at the optic nerve head as the optic nerve and retinal vessels enter the globe. PION occurs anywhere posterior from the optic nerve head to the optic chiasm. Early fundoscopic examination will demonstrate disc oedema in AION (Figure 1), whereas the fundus is entirely normal in early PION (Figure 2). Days to weeks later fundoscopy reveals optic nerve pallor in both conditions (Figure 3). Pupillary light reflexes are absent or delayed in both conditions and patients may complain of total blindness or altitudinal field defects (visual loss above or below the visual horizon). Delayed or worsening visual loss usually implicates AION as the probable diagnosis and the delay can be up to a few weeks after surgery.

In just over half of the ION cases in the American Society of Anaesthesiologists Post Operative Visual Loss (ASA POVL) Registry, both eyes were affected, suggesting a systemic event [1]. Complete recovery from either AION or PION is rare.

AION has been primarily associated with CPB procedures but can also occur during prone spine operations and spontaneously. PION is most commonly associated with lengthy prone spine operations and bilateral radical neck operations. Numerous contributory factors for AION and PION have been proposed (hypotension, anaemia, oedema, venous congestion, variations in ocular anatomy and physiology, effects of fluid resuscitation) but none has been causally linked [11,12]. Older patients are more at risk of ION due to the natural reduction in nerve fibres of approximately 5,000/yr [13].

Blood flow to the anterior optic nerve is autoregulated by endovascular and metabolic factors similar to

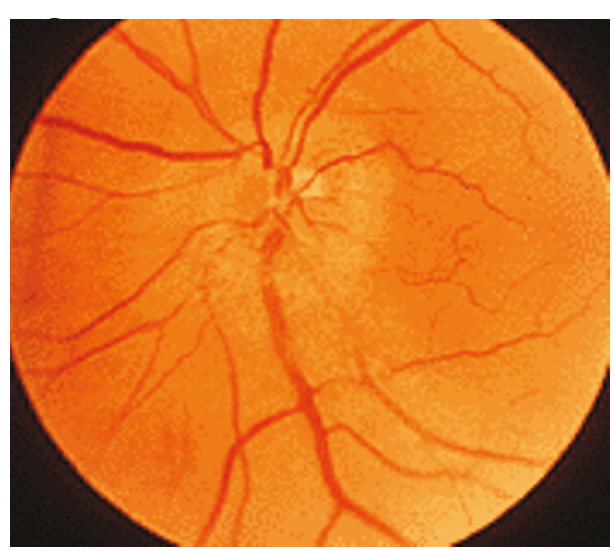

Figure 1 Early AION (note oedematous fundal appearance).

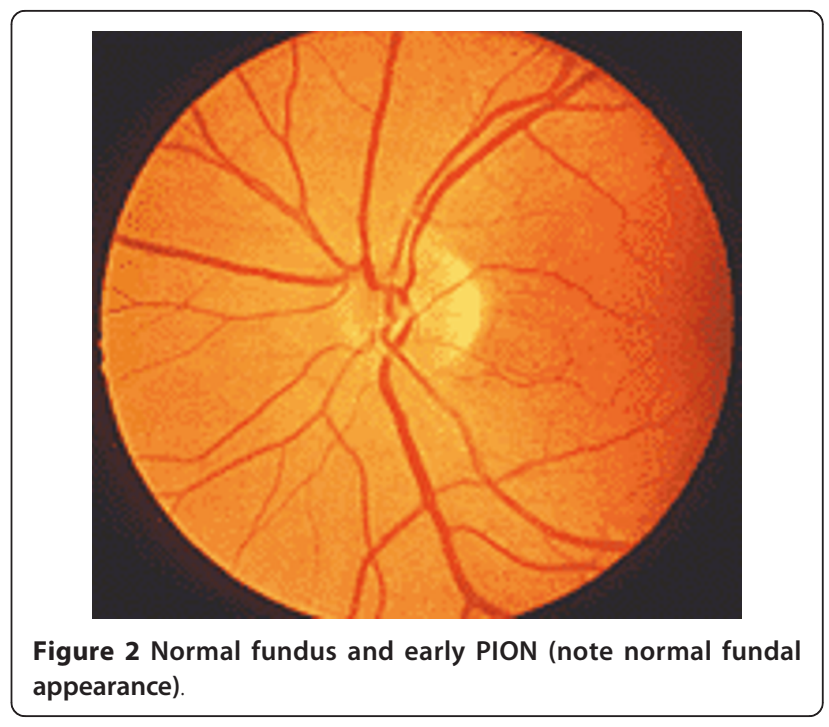

cerebral circulation. Autoregulation is effective over a critical range of perfusion pressure - not clearly defined in humans. Diseases of the circulatory system (hypertension, diabetes mellitus, atherosclerosis) damage autoregulation and therefore increase the critical perfusion pressure below which autoregulation of the anterior optic nerve fails. PION arises from the suboptimal blood supply from branches of the ophthalmic artery and the central retinal artery. The risk factors for both AION and PION in non-surgical patients include: high serum cholesterol and triglycerides, lipidaemia, fibrinogenaemia, DM and smoking. Risk factors in cardiac surgical patients include: intrinsic small vessel disease (DM), hyperglycaemia, hypertension, prolonged hypotension, vasospasm secondary to inotropes, the inflammatory process induced by $\mathrm{CPB}$, anaemia and lower than normal cup:disc ratio which correlates with small scleral

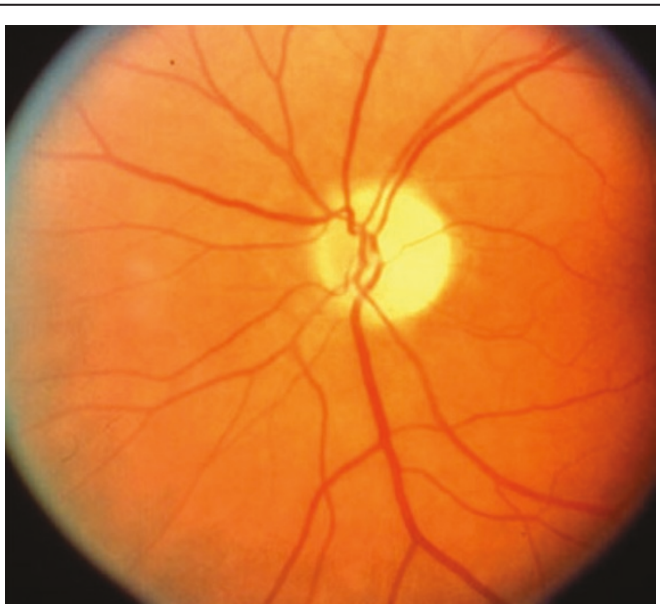

Figure 3 Late AION and PION (note pallor of fundal appearance) 
canal and possibly emboli [1]. A combination of risk factors in a patient may lead to additive or synergistic effects on blood flow and autoregulation.

A large retrospective time-matched, case-control study of 27,915 patients who underwent CPB was undertaken using the Mayo Clinic Surgical and Medical Indexes [6]. ION was identified in $17(0.06 \%)$ cases. 2 controls for each ION patient were chosen by selecting 2 patients who underwent $\mathrm{CPB}$ exactly 2 weeks before each ION patient. They found significant risk factors for postoperative ION following cardiac surgery using $\mathrm{CPB}$ to be: advanced age, lower minimum post-operative haemoglobin concentrations, history of clinically severe vascular disease, pre-operative angiogram within 48 hours of $\mathrm{CPB}$, longer pump times, surgical disruption of particulate matter, $\mathrm{RBC}$ transfusions and use of non-RBC blood components. Visual field and acuity loss was present in $100 \%$ of the cases and no improvement was found on follow-up.

Anaemia is an amenable risk factor to efficient correction. Nevertheless optimum haemoglobin concentration is a controversial subject especially in patients with cardiovascular disease. By contrast Spiess found that a higher haematocrit on intensive care admission was associated with Q wave MI [15]. Brown et al reported a series of 6 patients over a 10-year period that developed AION related to anaemia and hypotension after various surgical procedures [16]. There is debate as to whether cardiac patients behave similarly to other surgical patients [12]. Roth investigated the effect of isovolaemic haemodilution on ocular blood flow in cats [17]. He found a $71 \%$ increase in retinal blood flow and retinal $\mathrm{O}_{2}$ delivery remained approximately constant as the increased blood flow countered a significant decrease in arterial $\mathrm{O}_{2}$ content. Neely et al found feline retinal tissue oxygen tension increased initially during isovolaemic haemodilution to $50 \%$ above baseline at about $2 / 3$ of the original haematocrit level and beyond this a steady decline in tissue oxygen tension [18]. Among cardiac surgical patients Mansour carried out a retrospective chart review of 1594 consecutive CABG patients over a five-year period (1995-1999) in one medical centre [19]. 3 patients experienced visual loss due to anterior ischaemic optic neuropathy - all had diabetes mellitus and 2 suffered severe postoperative anaemia. Among diabetics the risk of anterior ischaemic optic neuropathy was significantly higher in subjects with a postoperative haematocrit below $22 \%$ compared with the non-diabetic population $(28.6 \% \mathrm{v} 0.21 \%, \mathrm{p}=0.001)$.

Increasing the transfusion threshold in an effort to correct anaemia may minimize the chances of ION. However, transfusion in cardiac surgery has been shown to increase morbidity and mortality. Engoren demonstrated that transfused cardiac surgical patients had a five-year mortality double that of non-transfusion group [20]. Similarly Kudavalli found increased one-year mortality in the transfusion group [21]. Habib found increased incidence of renal injury and Banbury found increased risk of infection after transfusion in cardiovascular surgery $[22,23]$. Surgenor found that treatment of anaemia with transfusion increased the risk of low output cardiac function requiring treatment with inotropes and intra-aortic balloon counter pulsation [24]. In Hebert's multicentre RCT, he found no significant difference in 30-day or 60-day mortality in ICU patients with significant cardiovascular disease whether restrictive or liberal transfusion triggers were used [14]. However restrictive transfusion triggers appeared to be associated with significantly lower mortality in younger patients with lower APACHE scores.

So, with regard to correction of anaemia it would seem that we are "damned if we do and damned if we don't - withholding transfusion may have a cost in terms of increased incidence of ION or renal failure but transfusion itself may increase morbidity and mortality [25]. The Society of Thoracic Surgeons and the Society of Cardiovascular Anaesthesiologists recommend transfusion thresholds $>7 \mathrm{~g} \mathrm{dl}^{-1}$ [26].

Given the concerns surrounding transfusion as a treatment for perioperative anaemia, it has been proposed that prophylactic measures to minimize bleeding might be the solution to the problem. In a meta-analysis by Laupacis, tranexamic acid administration was associated with lower transfusion requirements in patients undergoing cardiopulmonary bypass [27]. Nevertheless, a major concern with tranexamic acid use is the possibility of increased risk of thrombembolic events, however the evidence is weak at present [28].

Another risk factor for ION, which may be amenable to intervention, is patient positioning. Prone position is known to increase IOP and although prone positioning is not used routinely in cardiac surgical patients, they may develop a lung injury in the post-operative period either from the cardiopulmonary bypass itself, transfusion, or sepsis and I feel it is worth a mention. Ozcan looked at the effect of prone positioning in awake volunteers and found IOPs $50 \%$ higher in prone horizontal patients [29]. The rise in IOP could be reduced with head-up tilt of 10 degrees, but not to normal. Cheng found IOP doubled in prone anaesthetised patients [30]. The episcleral venous system is connected to the central venous system via a valveless arrangement such that an increase in CVP causes an increase in episcleral venous pressure and hence increased IOP. There have been many reports of ION following surgical procedures performed in the prone position. Proning is also increasingly used in intensive care to treat patients with ARDS and the effect on IOP should also be 
considered in these critically ill patients. A mild degree of reverse Trendelenberg may ameliorate the increased episcleral venous pressure caused by proning. There are as yet no published cases of blindness associated with proning in ARDS, but it is only a matter of time. We are proposing to carry out a survey of practice across hospitals in the geographical area in order to establish practice with regard to proning in ITU and actions taken to defend ocular perfusion. We also wish to carry out a preliminary crossover study measuring intraocular pressure and haemodynamic parameters in supine position before proning procedure and thereafter in prone flat and then with a moderate degree of head-up position.

Perfusion pressure of the anterior optic nerve is the difference between the ciliary artery and venous drainage - approximately MAP - IOP. Increased IOP may substantially reduce the perfusion pressure of the anterior optic nerve. Increased IOP may contribute to the higher incidence of ION after operations involving CPB. Sanjay et al showed that intraocular pressure (IOP) increases on commencement of $\mathrm{CPB}$ and maximally at 20 minutes to $21 \mathrm{mmHg}$ [31]. Methods to reduce IOP and therefore maximise intraocular perfusion pressure must be sought, including head position and use of loose endotracheal tube ties. CVP can increase beyond IOP and affect intraocular perfusion as it is a valveless system. This is in addition to external pressure on the globe [12]. Visual loss is not always associated with intraoperative hypotension, however it is quoted in a number of case reports $[5,12]$. Often the nadir of perfusion pressure is no different between those affected and unaffected after $\mathrm{CPB}$ and a modicum of hypotension is a frequent occurrence in anaesthetised patients, which may be associated with altered autoregulation or anatomical variation of optic nerve blood supply $[12,32,33]$.

Embolic phenomena are another possible cause of ION and may be related to aortic cross clamping [34]. In a prospective study of neurological complications of coronary artery bypass surgery in 312 patients, 25.6\% developed neuro-ophthalmological complications [35]. Horton showed visible retinal emboli in three patients, two coronary artery bypass graft patients using $\mathrm{CPB}$ and one cardiac catheterisation patient [36]. Intra-operative epi-aortic ultrasound may be a solution to minimise embolic risk for placement of the aortic cross-clamp. A "no-touch" technique may be used in off-pump CABG and alternative route CPB [37]. A sutureless proximal aortic anastamotic technique has been shown to reduce micro-embolic counts on transcranial Doppler [38].

The use of inotropes has also been implicated in cases of ION. Shapira et al found the development of AION in 8 patients out of 602 consecutive cardiac surgery patients $(1.3 \%)$, an increase from their usual $0.5 \%$ rate
[33]. Although it was impossible to implicate any single factor in the increased incidence, prolonged $\mathrm{CPB}$, lower haematocrit, and peri-operative use of adrenaline and amrinone were all found to be associated. In one case series of 4 patients with AION occurring within a onemonth period, high doses of mixtures of inotropes were one of the putative causes [39]. Adrenaline is postulated to cause severe vasospasm of the ocular vessels $[40,41]$. This presents anaesthetists with a difficult clinical decision since prolonged hypotension is also listed as a risk factor for ION.

In conclusion perioperative ION is a rare, devastating event, which may be difficult to detect in a sedated postoperative patient. The signs are subtle and are often late to present. Cardiac surgical procedures involving $\mathrm{CPB}$ appear to be at increased risk of causing this condition especially if complicated by hypotension, use of inotropes or anaemia. No effective treatment for ION exists, once established, hence prevention is crucial. Despite this, studies to date have only succeeded in demonstrating that minimizing one risk factor for the development of ION may merely serve to introduce another.

\section{Consent}

Written informed consent was obtained from the patient for publication of this case report and any accompanying images. A copy of the written consent is available for review by the Editor-in Chief of this journal.

\section{Author details}

'Department of Anaesthesia, Royal Group of Hospitals and Dental Hospital Health and Social Services Trust, Grosvenor Road, Belfast, BT12 6BA, Northern Ireland. ${ }^{2}$ Department of Cardiothoracic Transplantation \& Mechanical Support, Royal Brompton \& Harefield NHS Trust, Harefield, UB9 6JH, London, United Kingdom. ${ }^{3}$ Department of Critical Care, The Royal London Hospital, Whitechapel Road, E1 1BB, London, United Kingdom.

\section{Authors' contributions}

BT, LMCW and AFP wrote the paper. BT and LMcW performed the literature search. HG reviewed all drafts of the manuscript and suggested changes. BV SAP and RG added important comments to the paper. All authors have read and approved the final manuscript.

\section{Competing interests}

The authors declare that they have no competing interests.

Received: 2 June 2011 Accepted: 21 November 2011 Published: 21 November 2011

\section{References}

1. Lee LA, Roth S, Posner KL, Cheney FW, Newman NJ, Domino KB: The American Society of Anaesthesiologists Postoperative Visual Loss Registry. Anaesthesiology 2006, 105:652-9.

2. Roth S, Thisted RA, Erickson JP, Black S, Schreider BD: Eye injuries after non-ocular surgery. Anaesthesiology 1996, 85:1020-7.

3. Roth S, Black S, Erickson JP, Schreider BD: Ocular complications following anaesthesia for non-ocular surgery: review 59,000 cases. Anaesth Analg 1993, 76(Suppl):S357.

4. Williams ET: Postoperative ischaemic optic neuropathy. Anaesth Analg 1995, 80:1019-29. 
5. Myers MA, Hamilton SR, Bogosian AJ, Smith CH, Wagner TA: Visual loss as a complication of spine surgery. Spine 1997, 22:1325-29.

6. Nuttall GA, Garrity JA: Risk factors for ischaemic optic neuropathy after cardiopulmonary bypass: a matched case/control study. Anesth Analg 2001, 93:1410-16.

7. Burde RM: Optic disc risk factors for nonarteritic anterior ischaemic optic neuropathy. Am J Ophthalmol 1993, 116:759-64

8. Hayreh SS: Anterior ischaemic optic neuropathy. Clinical Neuroscience 1997, 4:251-63.

9. Dilger JA, Tetzlaff JE, Bell GR, Kosmorsky GS, Agnor RC, O'Hara JF: Ischaemic optic neuropathy after spinal fusion. Ca J Anaesth 1998, 45:63-66.

10. Bernstein SL, Guo Y, Kelman SE, Flower RW, Johnson MA: Functional and cellular responses in a novel rodent model of anterior ischaemic optic neuropathy. Invest Ophthalmol Vis Sci 2003, 44:4153-62.

11. Cullinane DC, Jenkins JM, Reddy S: Anterior ischaemic optic neuropathy: a complication after systemic inflammatory response syndrome. J Trauma 2000, 48:381-7.

12. Roth S: Perioperative visual loss: what do we know, what can we do? $\mathrm{Br}$ J Anaesth 2009, 103:31-40.

13. Mikelberg FS, Drance SM, Schulzer M, Yidegiligne HM, Weis MM: The normal human optic nerve:Axon count and axon diameter distribution. Am J Ophthalmol 1984, 97:760-6.

14. Hebert PC, Wells G, Blajchman MA, Marshall J, Martin C, Pagliarello G, Tweeddale M, Schweitzer I, Yetisir E: A multicentre, randomised, controlled clinical trial of transfusion requirements in critical care. $N$ Engl J Med 1999, 340:409-17.

15. Spiess BD, Ley C, Body SC, Siegel LC, Stover EP, Maddi R, D'Ambra M, Jain U, Liu F, Herskowitz A, Mangano DT, Levin J: Haematocrit value on intensive care entry influences frequency of Q-wave Ml after CABG. Thorac Cardiocasc Surg 1998, 116:460-7.

16. Brown RH, Schauble JF, Miller NR: Anaemia and hypotension as contributors to perioperative loss of vision. Anaesthesiology 1994, 80:222-6.

17. Roth S: The effects of isovolaemic haemodilution on ocular blood flow. Experimental Eye Research 1992, 55:59-63.

18. Neely KA, Ernest JT, Goldstick TK, Linsenmeier RA, Moss J: Isovolaemic haemodilution increases retinal tissue tension. Graefe's Archive for Clinical and Experimental Ophthalmology 1996, 234:688-94.

19. Mansour AM, Awwad ST, Najjar DM, Sibai AN, Medawar WA: Anterior ischaemic optic neuropathy after coronary artery bypass graft: the role of anaemia in diabetics. Eye 2007, 21:864-5.

20. Engoren MC, Habib RH, Zacharias A: Effect of blood transfusion on longterm survival after cardiac operation. Ann Thorac Surg 2002, 74:1180-86.

21. Kudavalli M, Oo Ay, Newall N, Grayson AD, Jackson M, Desmond MJ, Fabri BM, Rashid A: Effect of perioperative red cell transfusion on 30-day and 1-year mortality following coronary artery bypass surgery. Eur $J$ Cardiothorac Surg 2005, 27(4):592-8.

22. Habib RH: Adverse effects of low haematocrit during adult cardiopulmonary bypass: should current practice change? J Thorac Cardiovasc Surg 2003, 125(6):438-50.

23. Banbury MK, Brizzio ME, Rajeswaran J, Lytle BW, Blackstone EH: Transfusion increases the risk of post-operative infection after cardiovascular surgery. J Am Coll Surg 2006, 202:131-38.

24. Surgenor SD, DeFoe GR, Fillinger MP: Intra-operative red cell transfusion during coronary artery bypass graft surgery increases the risk of postoperative low output cardiac failure. Circulation 2006, 114:43-8.

25. Spiess BD: Choose one: damned if you do/damned if you don't! Crit Care Med 2005, 33(8):1871-74

26. Force SoTSBCGT (Society of Thoracic Surgeons Blood Conservation Task Force), Ferraris VA, Ferraris SP, Saha SP, Hessel EA, Haan CK, Royston BD, Bridges CR, Higgins RSD, Despotis G, Brown JR: Peri-operative blood transfusion and blood conservation in cardiac surgery: The Society of Thoracic Surgeons and The Society of Cardiovascular Anaesthesiologists clinical practice guideline. Ann Thorac Surg 2007, 83:S27-86.

27. Laupacis A, Ferguson D: Drugs to minimise perioperative blood loss in cardiac surgery: meta-analyses using perioperative blood transfusion as the outcome. The International Study of Perioperative Transfusion Investigators. Anesth Analg 1997, 85:1258-67.

28. Mahdy AM, Webster NR: Perioperative systemic haemostatic agents. BJA 2004, 93(6):842-58
29. Ozcan MS, Praetel C, Bhatti MC, Gravenstein N, Mahla ME, Seubert CN: The effect of body inclination during prone positioning on intraocular pressure in awake volunteers: a comparison of two operating tables. Anesth Analg 2004, 99:1152-8.

30. Cheng MA, Sigurdson W, Tempelhoff R: The effect of prone positioning on intraocular pressure in anaesthetised patients. Anaesthesiology 2001, 95(6):1351-1355

31. Sanjay OP, Prashanth P, Tauro DI, Francis J, Thomas A: Intraocular pressure changes during cardiopulmonary bypass. Ind I Thorac Cardiovasc Surg 2005, 21:157-60

32. Hayreh SS: In vivo choroidal circulation and its watershed zones. Eye 1990, 4:273-289.

33. Shapira O, Kimmel W, Lindsey PS, Shahian DM: Anterior ischaemic optic neuropathy after open heart operations. Ann Thorac Surg 1996, 61:660-6.

34. Breuer A, Furlan AJ, Hanson MR: Central nervous system complications of coronary artery bypass graft surgery: prospective analysis of 421 patients. Stroke 1983, 14:682-7.

35. Shaw PJ, Bates D, Cartlidge NEF, Heaviside D, French JM, Julian DG Shaw DA: Neuro-ophthalmological complications of coronary artery bypass graft surgery. Acta Neurol Scand 1987, 76:1-7.

36. Horton J: Embolic cilioretinal artery occlusion with atherosclerosis of the ipsilateral carotid artery. Retina 1995, 15:441-4.

37. Hangler HB, Nagele G, Danzmayr M, Mueller L, Ruttmann E, Laufer G, Bonatti J: Modification of surgical technique for ascending aortic atherosclerosis: impact on strokereduction in coronary artery bypass grafting. J Thorac Cardiovasc Surg 2003, 126:391-400

38. Scarborough J, White W, Derilus FE, Mathew JP, Newman MF, Landolfo KP: Combined use of off-pump techniques and a sutureless proximal aortic anastamotic device reduces cerebral microemboli generation during coronary artery bypass grafting. J Thorac Cardiovasc Surg 2002, 125:1561-7.

39. Lee LA, Nathens AB, Sires BS, McMurray MK, Lam AM: Blindness in the Intensive Care Unit: possible role for vasopressors. Anaesth Analg 2005, 100:192-5

40. Savino P, Burde R, Mills RP: Visual loss following intranasal anaesthetic injection. J Clin Neuroophthalmol 1990, 10:140-4

41. Ohkubo H, Chiba S: Vascular reactivities of simian ophthalmic and ciliary arteries. Curr Eye Res 1987, 6:1197-203.

doi:10.1186/1749-8090-6-154

Cite this article as: Trethowan et al: A case report and brief review of the literature on bilateral retinal infarction following cardiopulmonary bypass for coronary artery bypass grafting. Journal of Cardiothoracic Surgery 2011 6:154.

\section{Submit your next manuscript to BioMed Central and take full advantage of:}

- Convenient online submission

- Thorough peer review

- No space constraints or color figure charges

- Immediate publication on acceptance

- Inclusion in PubMed, CAS, Scopus and Google Scholar

- Research which is freely available for redistribution

Submit your manuscript at www.biomedcentral.com/submit
Ciomed Central 